\title{
A CONTENT ANALYSIS OF MEDIA INFORMATION EXPOSURE ON TOURISM DESTINATION IMAGE
}

\author{
I Nengah Laba. \\ Sekolah Tinggi Pariwisata Bali Internasional \\ laba@stpbi.ac.id
}

\begin{abstract}
This study examines the issue of the formation of destination image through the analysis of the specific tourism discourse. It is the linguistic variety of English used in tourism which was written by tourists on websites imaging the destination of the Campuhan Ridge. The study focuses on the way tourism discourse contributes to conveying an image of a destination using the approach of media exposure theory. Referring to previous scientific studies, tourism destination image has been shaped through the mediation between tourists' mental constructs and web-based tourism discourse. Using a theory of information media exposure and an approach of linguistic study, samples of texts from websites were examined and analyzed using qualitative content analysis. Results show that linguistic features seen from lexical and phrasal choices were used together with functional attributes, psychological attributes, Psychological-holistic impressions, and Common-Unique dimension when tourists describing tourism destination image.
\end{abstract}

Keywords: Tourism image, content analysis, attributes.

\section{Introduction}

The tourism industry is one of the most important socio-economic sectors in Bali. The industry has contributed to job creation. Many Balinese work in tourism industry. The development of the industry benefits both socially and economically. Socially, the countries benefit from, preservation of their culture, promotion of peace and encouragement of intercultural interaction. In economic terms, the industry contributes to, balance of payment, regional development and job creation (Hall, 2010). Despite its benefits, the tourism industry is vulnerable to many external factors such as social, political and economic factors that hinder the growth of the industry by distorting the image of the tourist destinations. For example, events such as terror attacks, political instability and war, natural disasters and epidemics have a negative impact on destinations (Beirman, 2003).

With the widespread of modern transportation vehicle and under the stimulation of internet and various information media technologies, the movements of tourists within home country and abroad for the last decades become an obvious social-economic phenomenon, and thus attract the attention from governments at different levels. Tourism, as a window of local public image, attracts the attention from cities, regions and countries all over the world. The flows of tourists among different regions and accompany the flows with information, goods and cash in the 
field of economy, trade, culture, science, technology and politics. In long term, the influence and penetration of the destination image can attract tourists. Many local tourism images become homogeneous, how to build a unique tourist destination image in the minds of target tourists becomes an important task.

As one of the most favorite tourist destinations in Bali, Ubud has attracted hundreds of tourists every month. There are many fantastic things to do in Ubud. There are some really nice walks, be it through the village, through rice fields or just a beautiful nature walk. The Campuhan Ridge walk is definitely at the top of the list of must-do walks when in Ubud. It is a beautiful walk which is filled with greenery and hills. More of a jungle or forest walk. Many tourists take a walk up to the hill to enjoy rice fields and terraces.

The Campuhan ridge is a beautiful paved walk and this walk definitely showcases the natural side to Ubud. The popular walk along the narrow spine between the eastern and western branches of Ubud's. It is an easily accessible opportunity not only to stretch your legs and get away from the traffic-clogged streets, but it also offers stunning vistas and a glimpse of village life. The walk is not strenuous, but there are a few uphill sections, and some stairs in places. The walk can be done as an eight-kilometer loop, along the ridge and back through the streets, taking about three hours, or a more commonly as a shorter walk along the ridge and returning the same way. The walk begins at the entrance of Warwick. As a tourist object and as tourism is a social phenomenon, the Campuhan Ridge relies on the positive destination images and how visitors expose them in the media. Destination images are mental representations held by individuals of places and defer depending on the information received or actual visits by individuals. Events such as political instability and natural disasters like currently happening in Palu and Lombok have negative impacts on destinations. They contribute to formation of negative destination images among potential visitors and tourist stakeholders. Interpretations of events by individuals depend on several factors such as sociodemographic characteristics, cultural and historical backgrounds.

Referring to this rationale, it is urgent to do study on destination image of the Campuhan Ridge from the context of tourists' comments about the destination with research questions; 1) what are the images of the Campuhan Ridge from the tourists' perspective? and 2) how do the functional and psychological characteristics relate to destination image of the Campuhan Ridge? In this study, the formation of destination images among both the foreign and domestic tourists visiting the Campuhan Ridge. The main objective of this study was to find out what the images of the Campuhan Ridge from the tourists' perspective and how the functional and psychological characteristics relate to destination image of the Campuhan Ridge. This study is aimed at describing the issues between the concepts and theories of destination image using an approach of media information exposure.

\section{Literature Review}

Destination image is one of the most researched topics in tourism due to its power to invoke certain images into tourists' minds. The value of the destination image to the local destination marketing organizations and other destination promoters is uncontestable due to its power to attract more tourists to the area (See Calantone, Di Benetto, Hakam \& Bojanic, 1989). Destination image influences tourists' decision-making in regards to where they will spend their vacation and money. The 
importance of the destination image for the consumers allows us to think of any destination from the consumer's perspective in terms of how they sense, understand, use and connect to the place (Kavaratzis and Ashworth, 2004). Kotler and Gertner (2004) define a destination image as:

"The sum of beliefs and impressions people hold about place. Images represent a simplification of a larger number of associations and pieces of information connected to a place. They are a product of the mind trying to process and pick out essential information from huge amounts of data about a place".

Ratkai (2004) has also looked at how destination image has been conceptualized by earlier researchers and came to the conclusion that, while many studies failed to define destination image, defining the concept has been difficult making it a subjective and abstract subject. However, most of the definitions found in San Martin and del Bosque's (2008) and Ratkai's compilations include terms such as "impression" and "perception" of tourists to describe the concept of destination image. The repetition of these terms reinforces the idea that the tourists are ultimately the ones who influence the way a destination is viewed by the world. Based on their personal impressions and perceptions described on and as media information exposure, tourists have the power to influence the tourism flow to any destination. In this context, media information exposure is defined as the intentional or unintentional disclosure of information to an actor that is not explicitly authorized to have access to that information. San Martin and del Bosque (2008), in their explanation of how destination images are formed, noted that the consumers' perception of a destination is based on information from different sources over time, which is selected, elaborated and embellished in order to have a meaningful existence. From San Martin and del Bosque's (2008) compilation of destination image definitions, one has particularly stood up due to its applicability to the particular case study presented in this research.

Murphy, Pritchard, and Smith (2000) have defined destination image as a sum of associations and pieces of information connected to a destination, which would include multiple components of the destination and personal perception. The associations and information relevant to the case of the Campuhan Ridge are largely based on induced images created by visitors on the travel online websites and weblogs. Based on these images which are often connected to Ubud destination image, consumers form mental images, perceptions and expectations of what they would encounter if they travel to Ubud Bali. In order to better understand how these images are formed, a closer look to numerous image formation frameworks is required.

Gunn (1988) noted that a consumer's destination image depends largely on external stimuli, which are also called image formation agents by Gartner (1993). As seen above, the creation of destination images are based on different personal and stimulus factors (Cf. Bologlu and McClearly, 1999); but also on perceptual and more abstract factors such as consumers' attributes and impressions of place. These factors allow images to become either organic or induced. Gunn (1988) introduced the notion of organic and induced images in tourism. Organic images are those come from unbiased sources, while induced images are based on marketing and promotional material. He created a model to show how different agents can 
contribute to the destination image formation. His model contains seven phases of the travel experience within which the image is constantly changing:

1. Accumulation of mental images about vacation experiences

2. Modification of those images by further information

3. Decision to take a vacation trip

4. Travel to the destination

5. Participation at the destination

6. Return home

7. Modification of images based on the vacation experience

The main stages of destination image formation are happening in state one, two, and seven where destination images are first absorbed, then changed based on additional information and later modified again based on the overall experience. In phases one and two, the destination images are created based on secondary information, while in phase seven they are modified based on first-hand experience. Thus, the images developed in phases one and two are induced images since they are coming from outside sources, while those created in stage seven are most likely organic images based on personal experience. Gartner (1993) suggested that the difference between induced and organic images is the number of control destinations have over what is being presented. In order for destinations to better understand from where these images originate, and to help destinations gain a greater control over the images being marketed, Gartner (1993) compiled a list of eight different image formation agents:

1. Overt induced I - traditional forms of advertising which promote a certain destination image to attract visitors; this can include television, brochures, radio, and other advertising outlets

2. Overt induced II - information received from tourism agencies which are not directly associated with a destination. The images portrayed by these agents might not be realistic since they are based purely on profits.

3. Covert induced I - the use of a recognizable spokesperson in order to overcome credibility issues, or any endorsement from satisfied consumers

4. Covert induced II - any published material where the consumer is not aware of the involvement of the destination promoters. This can include materials written by reporters who were invited to a destination by the local DMO

5. Autonomous agents - news and reports which are independently produced

6. Unsolicited organic - information not requested and provided by tourists who have been to a destination and believe have knowledge of it. This agent is most influential on people who do not have any or little images of a destination.

7. Solicited organic - information gathered from family or friends regarding a destination. This type of agent can be very influential due to the perceived credibility and trustworthiness between those offering the information and the future consumer.

8. Organic - information gathered by the tourist during a trip which holds the highest rank of credibility since it is based on personal experiences.

The first four agents are involved in inducing images to consumers because they are all largely based on marketing the destination upfront or behind a cover. While the fifth agent is more neutral, the last three agents are becoming more organic in nature because they tend to be largely based on consumer's experiences. 
The identification of these image agents allows marketing organizations to better manage these agents in order to project a better image and therefore a better brand. Destinations can choose which agents to use in order to build a more believable and realistic image. Their selection could be based on the agents' credibility, cost or involvement in the tourism industry (Gartner, 1993).

In order to benefit the destination, images have to be distinctive, appealing, simple, and most importantly, believable and should be based on reality (Kotler \& Gertner 2004). The important role of destination image, both in terms of understanding travel behavior and in designing effective tourism marketing strategies, underscores the need to develop a concept comprehensively. To comprehend the concept, tourism researchers have the benefit of accessing the methodologies which have been developed to measure product image in general. However, because of the more complicated and diverse nature of the tourism product, it may be necessary to develop more specific and more complex conceptual frameworks and methodologies in order to reliably and validly measure destination image. Etchner and Ritchie (2003) agreed that, individuals have some form of mental representation of destinations even though they have never visited the destination. For instance, when we randomly ask anyone about one of tourist destination in Bali, there is a high probability that people know about Ubud either via the media, travel agents or even by word of mouth from friends and relatives who have been visiting Ubud. Gartner (1993) argued that, the images held by individuals of places are not static and can change with time when individuals are exposed to further information from various information agents. Events such as terrorism, war and political instability, world cup tournaments and international conferences in a destination are responsible for changing the images of a destination. Tourists who visit Ubud have different images.

\section{Methodology}

The travel agent websites and relevant valid research articles published in journals were analyzed through qualitative content analysis. This analysis method allowed the researcher to make replicable and valid inferences from the observation data and research article contents (Kippendorff, 2004). Creswell (2002) points out that the advantage of using content analysis is that the researcher can gain in-depth understating of the language and words of the documents under investigation. Kippendorff (2004) notes that, in qualitative research, content analysis involves the close reading of relatively small amounts of data; the interpretation of verbal, pictorial, symbolic, and communication data; and the involvement of the researcher with the study of data interpretation.

Charmaz (2006:187) notes that qualitative research focuses on creating conceptual frameworks through building inductive analysis from the data and data categories are named and become the basis for the emerging theory. While meanings are more easily inferred from textual data, the personal web pages and blogs also included images or pictures takes by tourists who visited the Campuhan Ridge. These images were examined and meanings of what they represent were inferred in order to be able to apply them to the research. Both the textual and visual data were used to explore the tourists' images on the Campuhan Ridge. This was accomplished through a process of coding, building relationships between codes, and finally, generating themes that answered the main research questions and 
addressed the research goal. Data coding followed a process of careful examination and interpretation to be able to find the hidden meanings. This step was completed through line-by-line coding, which Daly (2007) notes that although it is called lineby-line coding, does not necessarily mean to code every line of text, but only the data that can offer codes relevant to the research objectives. Next, the codes were categorized into themes by finding the connecting relationships and overarching conditions between them. This process is called theoretical coding and was first introduced by Glaser (1978) in order to help the researcher explain how the main codes relate to each other in such a way that if a relationship is non-existent, the theory would not be plausible.

\section{Research Result}

This section explains the analysis process for each set of data. The data were constructed in different formats such as text and/or photographs, the latent meanings were extrapolated based on the subjective interpretation of the researcher and the guidance of the research questions. While some data were more straightforward, such as written text, the pictures analyzed required more in-depth interpretation. Each blog type - text or picture was first coded in different Word documents. For the text and picture blogs, the actual website was saved as a Word document. After a careful examination, each text blog was decomposed into "meaning units". A meaning unit is considered as "words, sentences or paragraphs containing aspects related to each other through their content and context" (Graneheim and Lundman, 2004).

Out of the 3 text blogs analyzed and their meaning units were extrapolated. The following step involved the condensation of the meaning units into more focused codes. These codes were generated subjectively, based on the research questions and the researcher's interpretation of the text. Charmaz (2006) notes that the second major step in analyzing the data is "focused coding". These codes are more selective and general because they reflect larger segments of the data. This process was accomplished through three steps. First, all the codes were reviewed and redundancies eliminated. This was followed by the categorization of similar codes into categories. The third and final step in the focused coding was to generate the main themes.

The formation of image has been initially described by Reynolds (1965) as the development of a mental construct based upon a few impressions chosen from a flood of information. In the case of destination image, this 'flood of information' has many sources including promotional literature (travel brochures, posters), the opinions of others (family/friends, travel agents) and the general media (newspapers, magazines, television, books, movies). Furthermore, by actually visiting the destination, its image will be affected and modified based upon firsthand information and experience.

The data below were taken from travel advisor website. They are about the destination images of the Campuhan Ridge perceived by tourists visiting the destination. Their perception and comments on the Campuhan Ridge described on the travel advisory website depict the images of the destination. The data are coded to be further analyzed using qualitative content analysis. Some of the data are described as follows; "Was worried it would be too long but it was just right. We were there at 7 am and it was perfect weather. Go earlier if you can, it's beautiful 
time with fewer people do you can get those pictures without the crowds. If you take the start from ibah Warwick there are signs to guide you; so no worries about going the wrong way (Sascha S, Saturday 10 Oct 2018)" "The walk is quite challenging if sunny throughout a day. But it is worth doing it. While you walk you can admire a truly local landscape with lush greenery. Towards the end of the walking track you will see beautiful properties and rice fields of locals and you will recharge your batteries for the walk back at one of many restaurants and places where you can eat and drink. Wear comfortable shoes and don't forget to take a big bottle of chilled water. (Marcin787878, Friday 9 Oct 2018); " Rare escape from the buzz of traffic and into the green Ubud hills. Bit tough with little ones but if your willing to carry them it's ok. Lots of couples enjoying what the locals refer to as 'Bukit Cinta' - Love Hill :) (Richard M. Thursday, 8 Oct 2018)"(data source: https://www.tripadvisor.com/Attraction_Review_the CampuhanRidge.html cited on 14 October 2018)

It is clearly seen from the descriptions on the texts above. Explicitly, tourists who have visited the Campuhan Ridge have good images about the destination. The good images are also known from the comments of the tourists writing, "you can get those pictures without the crowds"; you will see beautiful properties and rice fields of locals"; "Rare escape from the buzz of traffic and into the green Ubud hills". Using content analysis, these textual expressions implies good perception of the tourists about the image of the Campuhan Ridge (Cf. Bologlu and McClearly, 2002; Gunn, 1988; Roberts and Stanbury, 2005; and Gartner and Tasci, 2007).

Comparing the characteristics and attributes model proposed by Echtner and Ritchie (1993), the Campuhan Ridge can be explained as follows:

$>$ Functional Attributes: the Campuhan Ridge is in a perfect and fresh air location with easy access to Ubud and close to other tourist objects in the area such as Ubud Palace, Monkey forest, Goa Gajah and Ubud Art Market. This gives the visitors to decide to do other leisure activities such as shopping, enjoying the cultural landmark of Ubud or elephant riding in the northern part of Ubud.

$>$ Psychological Attributes: various recreational activities can be performed in the Campuhan Ridge such as family picnic up on the hill, getting involved with the friendly villagers to do farming, offering young children the opportunity to explore nature and culture in a safe and comfortable area with appropriate amenities.

$>$ Psychological-holistic impressions: this can be found in the combination between the nature and traditional culture of the locals welcome at the Campuhan Ridge.

$>$ Common-Unique dimension: there are examples or references to special events can be enjoyed by the tourists such as getting involved in village life while trekking on the Campuhan Ridge. 
This comparison can be depicted in figure 1 below.

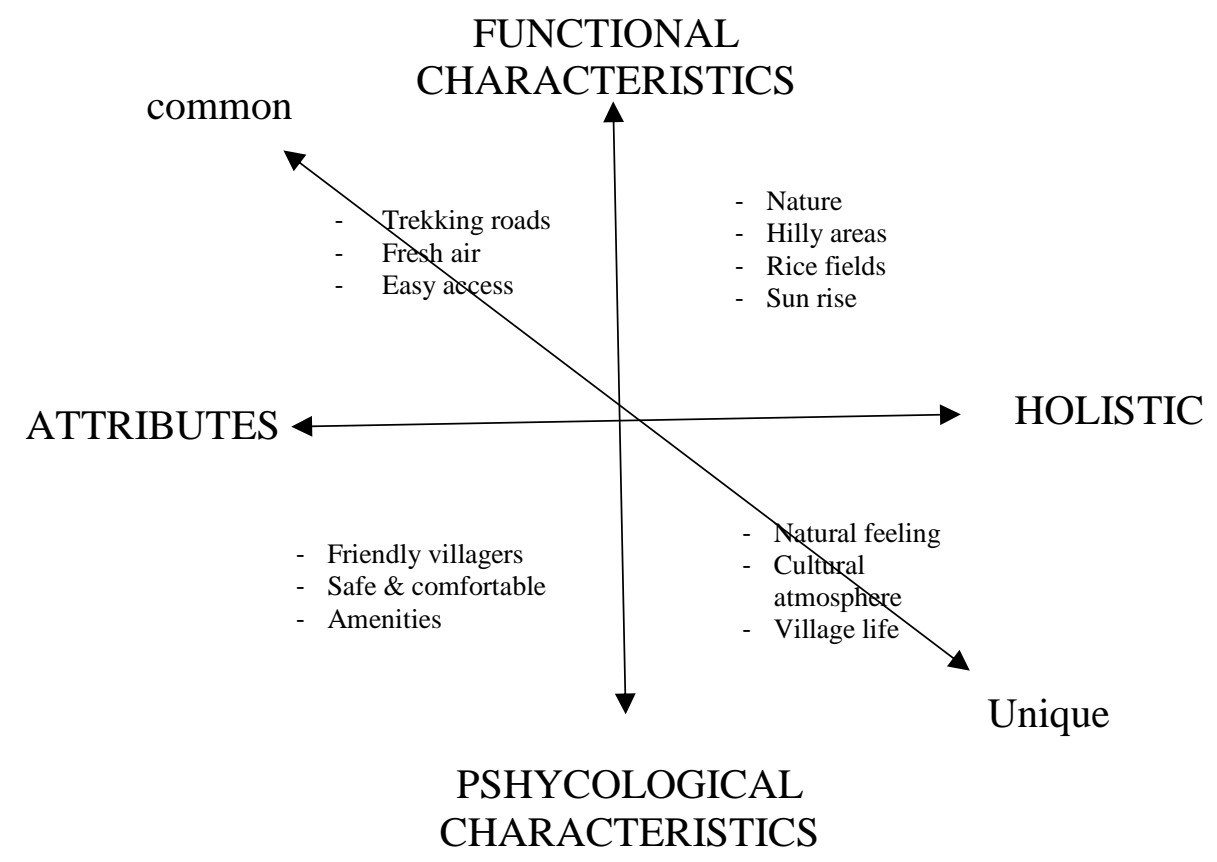

Figure 1: four components of destination image of the Campuhan Ridge. source: Echtner and Ritchie, 1993; 2003 modified by researcher

There were a few limitations affecting the manner in which this research was conducted that could have affected the results. These limitations include lack of data interview from tourists or respondents visiting the Campuhan Ridge and the inability to gather data from the locals and stakeholders such as tourism employees or tour guides. One of the main focuses of this study is on tourists' images of the Campuhan Ridge as expressed on Internet blogs and travel advisory website. In order to better understand the comprehensive image of a destination, future research should include groups from more nationalities such tourists from Asia, Europe or Middle East. Another alternative is to conduct a research on-site and interview all foreign tourists visiting the Campuhan Ridge. The data gathered would be based on the perceptions and impressions of tourists from all over the world. Another recommendation is to perform a quantitative follow-up study in which a larger, more random systematic sample would be used to provide more accurate proportions.

\section{REFERENCES}

Baloglu, S. and McClearly, K.W. (1999). A model of destination image formation. Annals of Tourism Research. 26(4), $868-897$. 
Charmaz, K. (2006). Constructing grounded theory: A practical guide through qualitative analysis. Thousand Oaks, CA: Sage Publications.

Creswell, J.W (2003) Research design qualitative, quantitative and mixed methods approaches. (2nd Ed.). London: Sage Publications.

Daly, K.J. (2007). Qualitative methods for family studies and human development. Los Angeles, CA: Sage Publications

Echtner, C.M, and Ritchie, J.R.B . (1991). The meaning and measurement of destination image. The Journal of Tourism Studies, 2(2), 2-12.

Echtner, C.M. and Ritchie, B. J.R. .(1993). The measurement of destination image: An empirical assessment. Journal of Travel Research. 31, p. 3 - 13.116

Gartner, W.(1993). Image formation process. Journal of Travel and Tourism Marketing 2(2/3):191-215.

Graneheim, U.H. and Lundman, B.(2004). Qualitative content analysis in nursing research: concepts, procedures and measures to achieve trustworthiness. Nurse Education Today, 24, 105-112.

Gunn, C. (1988). Vacationscape: designing tourists regions. New York: Van Nostrand Reinhold.

Kavaratzis, M. and Ashworth, G.J. (2005). City branding: an effective assertion of identity or a transitory marketing trick? Tijdschrift voor Economische en Sociale Gegrafie, 96 (5), 506- 514

Kotler, P and Gertner, D . (2004). Country as brand, product and beyond: a place marketing and brand management perspective. In Morgan, N., Pritchard, A. and Pride, R. (2002). Destination Branding: Creating the unique destination proposition. Burlington, MA: Elsevier.

Krippendorff, k (2004) Content Analysis: An Introduction to Its Methodology. $2^{\text {nd }}$ edition, Thousand Oaks, CA: Sage Publications.

Ratkai, S. (2004). Destination Image and the Influence of Different Forms of Information. Masters thesis. University of Waterloo, Canada.

San Martin, H. and del Bosque, I.A. (2008). Exploring the cognitive-affective nature of destination image and the role of psychological factors in its formation. Tourism Management. 29, 263 - 277.

Smith, S. (2009). Practical Tourism Research. Wallingford, UK: CAB International. 